\title{
Reflections on the Gestation of Polymorphic Innovation: The Exploitation of Emergence in Social Network Development via Text Messaging
}

\author{
John Lenarcic and Joan Richardson \\ School of Business IT and Logistics, RMIT University, \\ Melbourne, Victoria, Australia
}

John.Lenarcic@rmit.edu.au Joan.Richardson@rmit.edu.au

\begin{abstract}
The impact of mobile text messaging is re-interpreted as an emergent technology that has accidentally been instrumental in the configuration of new social networks on a global scale. Using the unintended consequences of this implicit revolution in interpersonal communication as a catalyst for the generation of ideas, the argument is advanced that this is a manifestation of a new type of creative communication which we have identified as Polymorphic Innovation, a quasiintuitive perturbation on conventional notions of originality in the business development process. This paper describes the qualitative data collected during a pilot of a Short Messaging service (SMS) system in a University. The effect SMS use had on communication style and the construction of social networks are discussed.
\end{abstract}

Keywords: Text Messaging, Social Networking, Innovation, Polymorphic innovation,

\section{Artefacts Used In Novel Ways}

What you are about to read is of a conceptual nature and non-standard in structure. The comments collected during focus groups conducted during and at the conclusion of the pilot of an SMS application are threaded through the discussion of the literature. Evidence of Polymorphic Innovation will be revealed.

"Emergence" is a complex systems process whereby the whole becomes greater than the sum of its parts (Johnson, 2001). This can also manifest itself as the ad hoc social phenomenon known as the law of unintended consequences (Merton, 1936). This notion refers to scenarios where actions that are undertaken result in unforseen side-effects and is more folk psychology than actual scientific law. It can be viewed as a variant of the apocryphal Murphy's Law, which can be stated as, "If anything can go wrong, it will go wrong" (Spark, 2006). Fitzgerald (2004) points out that serendipity often plays an important role in the design of useful products with the accidental inven-

Material published as part of this publication, either on-line or in print, is copyrighted by the Informing Science Institute. Permission to make digital or paper copy of part or all of these works for personal or classroom use is granted without fee provided that the copies are not made or distributed for profit or commercial advantage AND that copies 1) bear this notice in full and 2) give the full citation on the first page. It is permissible to abstract these works so long as credit is given. To copy in all other cases or to republish or to post on a server or to redistribute to lists requires specific permission and payment of a fee. Contact Publisher@InformingScience.org to request redistribution permission. tion of the Post-it note being a key example. Research with the original intention of developing a temporary adhesive, eventually diverted into the ubiquitous office communication aid produced by Art Fry and Spencer Silver for the $3 \mathrm{M}$ Corporation in late 1970s. Incidentally, given the constriction of the medium, the Post-it note can arguably be likened to an analogue precursor to contemporary mobile text messaging sys- 
tems: The 3M website (http://www.3m.com/us/office/postit/pastpresent/history ff.html) lists the "fun fact" that a 1998 workplace survey of over 1,000 U.S. employees, undertaken by the Gallup Organization and the Institute for the Future, revealed that the typical professional obtains around eleven Post-it@ Note messages on a daily basis.

Accidental outcomes may have either positive or negative benefits but they could also lead to a myriad of minor difficulties that simply hamper the progress of any project. An example of this is the rapid adoption of the word "hello" in the English due to the advent of the telephone in the $19^{\text {th }}$ century (Hawley, 2001). Lerer (2003) notes that American author Mark Twain was one of the first authors in the English language to promote the use of "hello" as a telephone greeting in his 1889 novel A Connecticut Yankee in King Arthur's Court. This is one example of technology as the driver of a pervasive change in language.

The advent of the Global System for Mobile communication (GSM) network standard in 1991 ushered in another example of emergent pervasiveness in technology: The short messaging service (SMS) was originally intended to be merely a paging mechanism alerting mobile users to incoming voicemail messages but it fast became a parallel communication modality in its own right that is also exercising a linguistic shift in our we converse (Peersman, Cvetkovic, Griffiths, \& Spear, 2000; Peersman, Griffiths, Spear, Cvetkovic, \& Smythe, 2000). The technology has driven a reduction in the length of messages in order to fit on the typical mobile screen.

\section{Innovations Become Pervasive and Impact on Behaviour}

Wams and van Steen (2003) define pervasive messaging as that component of pervasive computing that facilitates interpersonal communication between users of a system. They have developed a taxonomic structure for electronic messaging systems with the goal of providing a comparative template against which differences in existing electronic messaging systems can be determined. The argument that consistency is a hallmark to attain in the construction of pervasive messaging systems is central to their work. There are too many variations according to these authors, so they have introduced a messaging model called the Unified Messaging System that can imitate any of the panoply in current use.

In a naturally succinct cultural history of the device, Agar (2003) describes the mobile phone as an enabling mechanism to facilitate "constant touch" between those connected in what has become a dynamic and ever-present social network. The mobile phone is no longer perceived solely as a mere communications device: In the eyes of some, it has transformed itself into a fashion icon emblematic of a new kind of global culture based on the exchange of information via linkages of trust (Katz \& Sugiyama, 2006). The implications of this emergent trend are that incoming generations will view mobile phones as more than just hardware. They are ubiquitous personal items that are essential to some as catalysts for personal well-being due to the comfort that they facilitate via both emotional and aesthetic means. Indeed, preliminary research findings indicate that mobile phones appear to also have a direct measurable effect on human physiology, particularly impinging on neural function subject to exposure duration with the devices (Croft et al 2002; Curcio et al 2005).

By creating a mobile information system in the vernacular of the user, namely the nascent idiolect of text messaging, control is assigned primarily to the consumer who can then extract what they need and when they need it. Computer-mediated forms of communication such as e-mail, instant messaging and texting have been observed as representing a stylistic evolution in natural language. Baron (1998) observed that e-mail was evolving into a hybrid form of interpersonal communication that combined the structures of writing with the informality of speech. In Baron (2005) similar comments were advanced with respect to instant messaging, a technological cousin of text messaging. Instant messaging is a near-synchronous, desktop computer-constrained 
communication system that approximates real-time chat in a dyadic modality. Nardi, Whittaker and Bradner (2000) talk of instant messaging providing a platform for both interaction, or simple information exchange and "outeraction.": The latter neologism being the social context within which the information is transacted.

Horst and Miller (2005) outline anthropological research undertaken in Jamaica indicating lowincome members of the community use mobile phones to create far-reaching social networks. The authors identify this new practice as "link-up" and speculate that these networking strategies are in fact adapted from existing Jamaican kinship and genealogy systems. So, link-up has been observed to facilitate the formation of spiritual and church communities, assisted in the search fro sexual partners and provided a conduit for the coping strategies embraced by low-income households. Therefore, to engage in link-up the mobile phone has become an essential technology in Jamaica. Stone's (2004) study at Kingston University in the UK utilised SMS technology to communicate with a large group of first year undergraduate students. The technology was used to provide appropriate resources and procedures in a timely manner, and to assist in the creation of social networks amongst the student group. In both of the aforementioned cases the SMS technology was used to facilitate the creation of social networks.

With its informal focus on brevity, text messaging should be exploited as a colloquial interface to systems applications for the very reason that it is a "short message service" by definition. Its emergence as the argot of an up-and-coming generation coincidentally parallels the recent observation that the same cohort are growing to shun detailed reading per se (Crain, 2007). Roach (2006) reports that the University of Cincinnati (UC) in the USA has initiated a voluntary scheme that provides all new students with a free mobile phone, subject to the user subscribing to the UC Mobile plan. The rationale is that mobile phones offer a relatively low-cost, wireless-based distribution node for the exchange of academic and campus information, as well as being a help button to contact emergency services.

\section{SMS Becomes Pervasive}

Generational cohorts familiar with the technology are comfortable with the modifications to the language and appreciate the convenience imbued by a device that dissolves the strictures of time and place that traditionally shackled communication and thrusts the action under the control of the user. One of the simple but attractive features of SMS is the fact that it is a "store and forward" service, meaning that if the receiving mobile phone is out of range or disabled then the network can store the message until a suitable connection is found (Dettmer, 1997; Faulkner \& Fintan, 2005). SMS technology, according to Faulkner and Fintan (2005), reflects attributes of Email in that it is asynchronous and enables automatic reply without having to recall an address or phone number.

The simplicity of the device, coupled with its massive global popularity, has meant that the mobile phone is becoming a convenient means of establishing improvised social networks such that the need for PCs in some cases is supplanted. Marshall (2007) reports that some rural communities, in countries where phone landline connections never existed are benefiting from speech and text communication in real time through the use of basic mobile phones. One more sophisticated mobiles, photo and video-recording options permit the sharing of information about farming practices. The interchange of image data via mobile phones has proven to be useful in business transactions involving illiterate customers. The nature of the device has enabled it to be persuasive across differing functions.

Within the ambit of ubiquitous computing, McDonald (2003) outlines a category known as recommendation systems through which users can deal with information overload through filtering content or de-stressing situations by providing options to assist in making a choice. A current 
business application of this is the SMS update service offered by Connex, the operator of the train system in Melbourne, Australia (www.connexmelbourne.com.au). From Monday to Friday, between 6am and 8pm, Connex offers service subscribers instant text messaging to mobile phones with the latest information on any train that is over 15 minutes past its scheduled departure time. The service also provides 24-hour SMS-delivered timetables that can be customised to a customer's needs. The next four trains departing from a customer's nearest station can be included in a text message and a SMS timetable can include all connecting services should the need arise to change trains.

Pervasiveness is also an underlying goal in the development of mobile systems for non-intrusive student administration within the higher education sector. The quest for nonchalant ubiquity in how a bureaucracy portrays itself to consumers is an attempt to reduce it to second nature. The labyrinthine hierarchies and numerous regulations in place to control activity in large organizations such as universities are often daunting to adapt to for new students. Raley (2007) reported on U.S. research that indicated that whether a person stays in university or not depends on how well that student socially integrates into the higher education community. Harley, Winn, Pemberton, and Wilcox (2007) argue that texting can assist in the transition process for new undergraduates, building on work by earlier researchers such as Riordan and Traxler (2005) who also extolled its benefits in augmenting student support, inclusion and retention. Wellman (2001) noted that computer networks are inherently social networks that connect people, organisations and knowledge. He advocated that such networks should not be studied in isolation as mere technical artefacts. On the contrary, they should be engineered to be the ambient texture of everyday lives and observed for the novelties that can emerge from the network-user symbiosis. Harley et al. (2007) document a system called Student Messenger that permits staff to send text messages from their desktop computers to the mobile phones of students. However, the setup does not facilitate two-way communication. A similar system known as StudyLink (Naismith, 2007) is an email-to-text delivery platform for student administration usage. This too lacks the capacity for true bi-directional interactions, an attribute that is a crucial aspect of another system known as Trigger (Richardson \& Lenarcic, 2007).

\section{Research Method}

A project based methodology was used to support fast development of an SMS prototype designed for use in the higher education sector. Staff volunteered to push reminders and provide 'on-demand' access of logistical information to students. Students volunteered to receive and access SMS communications. Academics and students using the system provided their opinions with respect to the effectiveness and usefulness of the technology application.

Focus groups were conducted to collect qualitative information from academic course coordinators that had been involved in the trial. This part of the process was designed to enable collection of data that detailed unplanned useful technical applications and functionality. Participants were asked to identify the useful features and functionality of the SMS prototype.

\section{Agile Development Increases Polymorphic Innovation}

What is innovation? Flowers (2008) refers to it as a constellation of methods that seize new ideas and transforms them into mass-market application. It differs from the concept of invention primarily in that these processes deal with either the commercial implementation of a new product or service, as well as its possible drastic or incremental enhancement. So, innovation can be considered as having two primary attributes: a high-quality idea and an encompassing infrastructure to promote that idea (Schwartz, 2008). The latter author also suggests the additional proviso that innovation needs an openness to change, coupled with private property rights to secure monetary returns for the developer. During the academic focus groups a great deal of resistance to change 
was expressed as they were reluctant to use the message push facility and requested additional training and assistance to ensure that the construction of their SMS was appropriate for the audience.

But what of other values, apart from the financial incentive, that could also drive innovation? Lenarcic and Mousset (2004) argue that the need to seek out a suitable aesthetic framework is a motivating impulse amongst the open source software community: a vast social network of innovation on the Web where the ebb and flow of creativity is regulated by status accorded to those who can transform the fragmentary seed of an embryonic software product into that which is in a relative state of conceptual elegance. Some open source software projects have been classed as being examples of "horizontal innovation networks" where the user of the innovation is also the manufacturer guiding the creative process (von Hippel, 2007). This egalitarian approach to innovation is top-down in nature with the process initially taking root from a high-concept idea planted by a single individual that is then augmented through the "wisdom of crowds" (Surowiecki, 2005), the latter throng being those who would use the innovation. Parallel to this, Flowers (2008) coined the term "Outlaw Innovation" to denote the emergence of legitimate innovation arising from the illegal activities of computer hackers. In this case, positive benefits can evolve from a nefarious initial stimulus, something that is akin to the US legal metaphor commonly known as "the fruit of the poisonous tree."

How does all this relate to the social phenomenon of text messaging? As previously noted, SMS was an invention that accidentally became an innovation. However, the social networks themselves are often the product of SMS usage, so the two exist in symbiosis with scope for continuous augmentation of one or the other. Given the ecological metaphor implicit in this assumption, we propose the notion of Polymorphic Innovation. Polymorphism is a term derived from the Ancient Greek and means "many forms". It is a word common in technical use within biology, botany and object-oriented programming (e.g., Yen \& Juang, 1991). Within the domain of objectoriented programming it is a key feature and describes the ability within a software system for different classes of objects to respond to the same set of messages. In a comparable manner, Polymorphic Innovation implies that the same invention can incite different groups of individuals to offer alternate patterns of use for the device or service, such as in the case of text messaging.

The prototype was used by academics to notify the students that assessment results were available. Students' however, requested modifications to the process trialled:

- "Push or send me results rather than me sending a message"(Student Respondent 1)

- "DLS alerts are unnecessary and it is pointless to send an SMS as well."(Student Respondent 3)

- "Reminders to start studying for an exam in September which are not necessary" and "Getting reminded about extra work (to poke your conscience) is nagging."(Student Respondent 5)

\section{Polymorphic Innovation}

Polymorphism as a theoretical framework has even been appropriated by the fine arts community, with Gaudnek (1970) describing a fixed image on a painter's canvas as ontomorphic, while one that changes in or with time as being polymorphic. The latter refers to the development of continuously unfinished paintings. In an alternative circumstance, this can also correspond to the scenario where an invention, for example, is in actual fact a prototype and not a finished product, which is usually the case prior to the genesis of conventional innovation. Polymorphic Innovation entails that innovation per se is a continuum with a point of conception but devoid of definitive retirement. 
Through this lens of meaning, Polymorphic Innovation is the set of tacit processes that determine, evaluate, implement and market the multiplicity of unanticipated possible uses that could exist for a given invention. Take the humble paper clip, for example, invented by Johan Vaaler in 1899: A device originally designed merely to hold papers together has found many disparate uses, such as being unwound to clean smoking pipes, finger-nails or even human ears (Naj, 1995)!

One could describe a paper clip as possessing multiple affordances. Gibson (1979) defined an affordance as the potential for action that is latent in an environment, which can be represented as the physical attributes of an object, say, that influence how it can be used by someone, dependent on their capabilities. An affordance refers to a physical property of something that influences how it can be used. For example, the shape and weight of hammer has a bearing on how one can use it effectively. The shape of a paper clip was a conscious design feature engineered to improve its initial targeted functionality, according to Petroski (1996), but with necessity being the mother of invention, as it often is, novel applications for the clip were discovered by those with the capacity to do so. Inu (1996) speculates that idyllic conditions generate little or no need for a comprehensive insight into of the source of an inconvenience because problems would not exist in a perfect world. As he quips: "If necessity is the mother of invention, problems may be the mother of research" (Inu, 1996, p. 770). The prototype was used to send class scheduling information and assessment reminders. The students participating in the focus group were clear about the type of SMS and when they wanted to receive them:

- Lecture locations were only useful at the start of semester

- SMS to book time with teachers

- Lecture location changes and cancellations

- Useful for library due dates

- $\quad$ SMS for assessment details rather than searching the web

- SMS would be more useful for courses where there is assessment occurring each week

- Reminders close to the exam of the date and seat allocation were thought to be useful, as were assessment dates and feedback. However reminders for tutorial dates were not considered necessary.

Emanating from the domain of anthropology, bricolage is a term signifying the recitation of a creative undertaking established on extemporization and the opportunistic use of limited resources that are subject to constraints (Levi-Strauss, 1966). The limited supply of 160 characters that constitute the expanse of a single text message compels the texter to adopt a bricoleur strategy in order to relate cogent meaning and this becomes a shared approach to generate a dynamic mobile social network. Some academics participating in the focus groups at the end of cited a lack of familiarity with the language commonly used by students as a constraint to use of the SMS application for broadcasting to their student groups. In order to remove this constraint a student translated, recorded and sent SMS messages in semester 2. Standard sentences, such as, "ISYS2056 - To revise for the exam start now doing the Sample Exam Question on DLS each week" were changed to "ISYS2056 - 2 rvse $4 \mathrm{~d}$ exm start nw doin d Smple Exm Ques on DLS ech wek". Polymorphic Innovation mirrors the ad-hoc, craft-like nature of bricolage.

Products are often designed to be easy to use, but perhaps sometimes they may become too easy to use in which case their utility in application is almost an unconscious process for the consumer. This is certainly not the case with text messaging, given the obvious systemic constraint of 160 characters, being the maximum size of a single communication. Lenarcic (2006) argues that a calibrated increase in the level of difficulty perceived within the interface of a device can accen- 
tuate cognisant engagement with the appliance. The rationale here is that awareness of a hindrance can promote inspired efforts to minimise or remove said encumbrance. On a pan-cultural basis, humanity is said to share the common trait of possessing a "puzzle instinct" (Danesi, 2002), an innate propensity to grapple with problems or enigmas that challenge ingenuity. The puzzle of text messaging is an ongoing challenge to craft miniscule missives, malformed in appearance perhaps, but with cohesive meaning that at times may appear to border on lyrical composition, a kind of digital incarnation of Japanese haiku poetry (Minami \& McCabe, 1991)

Aarseth (1997, p. 179) defines ergodic communication as that which "in a material sense includes the rules for its own use, a work that has certain requirements built in that automatically distinguishes between successful and unsuccessful users. " In other words, communication that has an embedded level of difficulty that demands a measured effort to both utilize and understand. The genre of ergodic literature is an extension of this and Russell Hoban's novel "Riddley Walker" (Hoban, 1980) is an example: A parable of speculative fiction that weaves a tale of survivors in a post-apocalyptic Britain, sometime in the future. The story is told as a first-person narrative in the fragmented dialect of English belonging to that era, an argot that bears an uncanny resemblance to present-day text messaging-speak! Ergodic communication (and literature) may require non-trivial efforts to comprehend and, to the uninitiated, text messaging would also fall into this category. But the price of the added exertion can result in additional vantages of meaning or allied inspirations.

The habit of seeking out the simplest option when innovating may not ultimately yield as many imaginative solutions as possible. This can be attributed in part to the lingering proverbial shackles of Occam's Razor: Webb (1996, p. 397) states that the 14th century dictum advanced by William of Occam is translated from the Latin as follows, "Plurality should not be assumed without necessity. " Over the centuries this has morphed into the maxim that the simplest solution to a problem is the best one to adopt. This bias of Occam's Razor has been criticized in several quarters, such as the aforementioned Webb (1996) and Pecker (2004) who stated that although the principle could excise redundant technicalities, it could also stifle the germination of imaginative theories and, by default, ancillary innovations. To capture the essence of Polymorphic Innovation, Occam's original saying can subtly paraphrased as, "Plurality should be assumed when necessity arises."

One object (or service) can possess many forms of use that can be discovered given a need. Based on anecdotal evidence, it is speculated that Polymorphic Innovation occurs in a cascading a fashion: Someone tinkers with an invention and finds a new use. Others observe this and experiment with tangential variants until another novelty emerges. One thing often leads to another until a critical mass is reached, as noticed by Ball (2004) who commented at length on the interplay of chance and necessity in the way that cooperation and conflict arise within human culture, customs and institutions. This is similar to the "tipping point" concept as advanced by Gladwell (2000) or the even earlier observation by Schumpeter (1939) that "swarms" or "bunches" of innovations can through diffusion spur expansion in the economy. Another related concept is the transmission of ideas via intangible constructs called "memes," these being units of cultural diffusion that are imitated in an anarchic fashion and often altered in the process in a comparable manner to genes (Dawkins, 1976). Innovation at times can happen in punctuated bursts that become a social epidemic, a case-in-point being the rapid take-up of text messaging by today's youth.

\section{Courage through Innovation: A Reflective Epilogue}

The folklore surrounding innovation that underpins successful entrepreneurship points to risktaking as being one of its primary elements (Brockhaus, 1987). Without a doubt, some would contend that the urge to gamble in its myriad varieties is a fundamental trait of the human species as such (e.g., Morris, 1967). Then again, Schumpeter (1934) believed that the compulsion to in- 
novate was a principal factor of entrepreneurship. Perhaps one can consider risk-taking to also play an important role in successful innovation: If originality is a virtue, then the act of going out on a limb to discover new applications of inventions demands a degree of courage. And what is courage but fortitude to take risks for the greater good and not bow down to the mediocrity of blind imitation.

\section{References}

Aarseth, E. (1997). Cybertext: Perspectives on ergodic literature. Baltimore, MD: Johns Hopkins University Press.

Agar, J. (2003). Constant touch: A global history of the mobile phone. Cambridge: Icon Books UK.

Ball, P. (2004). Critical mass: How one thing leads to another? London Heinemann.

Baron, N. S. (1998). Letters by phone or speech by other means: The linguistics of email. Language and Communication, 18, 133-170.

Baron, N. S. (2005). Instant messaging and the future of language. Communications of the ACM, 48(7), 2931.

Brockhaus, R. H. (1987). Entrepreneurial folklore. Journal of Small Business Management, 25(3), 1-6.

Crain, C. (2007, Dec. 24 \& 31). Twilight of the books. The New Yorker, pp. 134-139.

Croft, R. J., Chandler, J. S., Burgess, A. P., Barry, R. J., Williams, J. D., \& Clarke, A. R. (2002). Acute mobile phone operation affects neural function in humans. Clinical Neurophysiology, 113, 1623-1632.

Curcio, G., Ferrara, M., Moroni, F., D’Inzeo, G., Bertini, M., \& De Gennaro, L. (2005). Is the brain influenced by a phone call? An EEG study of resting wakefulness. Neuroscience Research, 53, 265-270.

Danesi, M. (2002). The puzzle instinct: The meaning of puzzles in human life. Bloomington, IN: Indiana University Press.

Dawkins, R. (1976). The selfish gene. New York: Oxford University Press.

Dettmer, R. (1997). Short message gets longer. IEE Review, 43(3), 104.

Faulkner, X., \& Fintan, C. (2005). When fingers do the talking: A study of text messaging. Interacting with Computers, 17, 167-185.

Fitzgerald, M. (2004). Engineering design concepts. Tech Directions, 63(7), 19-21.

Flowers, S. (2008). Harnessing the hackers: The emergence and exploitation of outlaw innovation. Research Policy, 37(2), 177-193.

Gaudnek, W. (1970). Polymorphism in painting through the use of a labyrinth. Leonardo, 3(2), 149-158.

Gibson, J. J. (1979). The ecological approach to visual perception. Boston, MA: Houghton Mifflin.

Gladwell, M. (2000). The tipping point: How little things can make a big difference. Boston, MA: Little, Brown.

Harley, D., Winn, S., Pemberton, S., \& Wilcox, P. (2007). Using texting to support students' transition to university. Innovations in Education and Teaching International, 44(3), 229-241.

Hawley, M. (2001). Waiting for linguistic Viagra. Technology Review, 104(5), 25-27.

Hoban, R. (1980). Riddley Walker. New York: Summit Books.

Horst, H., \& Miller, D. (2005). From kinship to link-up: Cell phones and social networking in Jamaica. Current Anthropology, 46(5), 755-778.

Inu, T. S. (1996). The virtue of qualitative and quantitative research. Annals of Internal Medicine, 125(9), $770-771$ 
Johnson, S. (2001). Emergence: The connected lives of ants, brains, cities and software. London: Allen Lane.

Katz, J. E., \& Sugiyama, S. (2006). Mobile phones as fashion statements: Evidence from student surveys in the U.S. and Japan. New Media \& Society, 8(2), 321-337.

Lenarcic, J. (2006). The antiusability manifesto. OZCHI '06: Proceedings of the 20th conference of the Computer-Human Interaction Special Interest Group (CHISIG) of Australia on Computer-Human Interaction: Design: Activities, artefacts and environments, Sydney, Australia, Nov. 20-24, 2006, pp. 337-339.

Lenarcic, J., \& Mousset, E. (2004). The open source singularity: A postmodernist view. Computing and Philosophy Conference, Canberra. Conferences in Research and Practice in Information Technology (Eds. J. Weckert and Y. Al-Saggaf), Vol. 37, pp. 73-77.

Lerer, S. (2003). Hello, Dude: Philology, performance and technology in Mark Twain's Connecticut Yankee. American Literary History, 15(3), 471-503.

Levi-Strauss, C. (1966). The savage mind. Chicago, IL: University of Chicago Press.

Marshall, J. (2007). If a phone can do the job, who needs a PC? New Scientist, 195(2615), 24-25.

McDonald, D. W. (2003). Ubiquitous recommendation systems. IEEE Computer, 36(10), 111-112.

Merton, R. K. (1936). The unanticipated consequences of purposive social action. American Sociological Review, 1(6), 894-904.

Minami, M., \& McCabe, A. (1991). Haiku as a discourse regulation device: A stanza analysis of Japanese children's personal narratives. Language in Society, 20(4), 577-599.

Morris, D. (1967). The naked ape. London: Corgi Books.

Naismith, L. (2007). Using text messaging to support administrative communication in higher education. Active Learning in Higher Education, 8(2), 155-171.

Naj, A. K. (1995, July 24). Hey, get a grip! Your basic paper clip is like a mousetrap. It's hard to improve, and few seem to be beating a path to the inventors' doors. The Wall Street Journal, p. A1.

Nardi, B. A., Whittaker, S., \& Bradner, E. (2000). Interaction and outeraction: Instant messaging in action. Proceedings of the 2000 ACM conference on computer-supported cooperative work, Philadelphia, Pennsylvania, Dec. 2-6, 2000, pp. 79-88.

Pecker, J-C. (2004). The provocative razor of William of Occam. European Review, 12(2), 185-190.

Peersman, G., Cvetkovic, S., Griffiths, P., \& Spear, H. (2000). The global system for mobile communications short message service. IEEE Personal Communications, 7(3), 15-23.

Peersman, G., Griffiths, P., Spear, H., Cvetkovic, S., \& Smythe, C. (2000). A tutorial overview of the short message service within GSM. Computing \& Control Engineering Journal, 11(2), 79-89.

Petroski, H. (1996). Invention by design: How engineers get from thought to thing. Cambridge, MA: Harvard University Press'.

Raley, Y. (2007). Why we quit. Scientific American Mind, 18(4), 74-79.

Richardson, J., \& Lenarcic, J. (2007). SMS Student Communication: Towards an understanding of the behavioural intention of the student population towards the use of a mobile academic information delivery system. 20th Bled eConference, eMergence: Merging and Emerging Technologies, Processes, and Institutions, Bled, Slovenia, June 4-6, 2007.

Riordan, B., \& Traxler, J. (2005). The use of targeted bulk SMS texting to enhance student support, inclusion and retention. Proceedings of the 2005 IEEE International Workshop on Wireless and Mobile Technologies in Education (WMTE'05), Tokushima, Japan, Nov 28-30, 2005, pp. 257-260.

Roach, R. (2006). University of Cincinnati offers free cell phones to incoming freshmen. Diverse Issues in Higher Education, 23(13), 31. 
Schumpeter, J. A. (1934). The theory of economic development: An inquiry into profits, capital, credit, interest and the business cycle. Cambridge, MA: Harvard University Press.

Schumpeter, J. A. (1939). Business cycles: A theoretical, historical, and statistical analysis of the capitalist process. New York: McGraw-Hill.

Schwartz, S. (2008, February 25). Innovation requires a free hand. The Australian Financial Review, p. 38.

Spark, N. T. (2006). A history of Murphy's Law. Los Angeles, CA: Periscope Film.

Stone, A. (2004). Mobile scaffolding: An experiment in using SMS text messaging to support first year university students. School Of Computing and Information Systems, Kingston University, UK., IEEE International Conference on Advanced Learning technologies (ICALT'04).

Surowiecki, J. (2005). The wisdom of crowds: Why the many are smarter than the few. London: Abacus.

von Hippel, E. (2007). Horizontal innovation networks - by and for users. Industrial and Corporate Change, 16(2), 293-315.

Wams, J. M., \& van Steen, M. (2003). Pervasive messaging, PerCom 2003 Proceedings of the First IEEE International Conference on Pervasive Computing and Communications, Forth Worth, Texas, Mar.2326, 2003, pp. 499-504.

Webb, G. I. (1996). Further experimental evidence against the utility of Occam's Razor. Journal of Artificial Intelligence Research, 4, 397-417.

Wellman, B. (2001). Computer networks as social networks. Science, 293, 2031-2034.

Yen, J., \& Juang, H-L. (1991). Using polymorphism to improve expert system maintainability. IEEE Expert, 6(2), 48-55.

\section{Biographies}

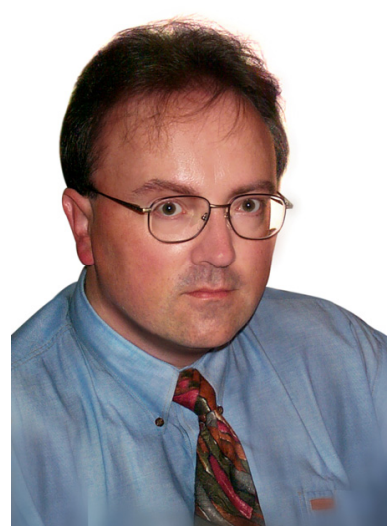

John Lenarcic is a Lecturer in the School of Business IT and Logistics at RMIT University in Melbourne, Australia. He is a physicist and applied mathematician by training, an IT academic by fortunate accident and an armchair philosopher by conscious choice. John's research interests include linguistic issues in informatics and the ethical and social aspects of information systems.

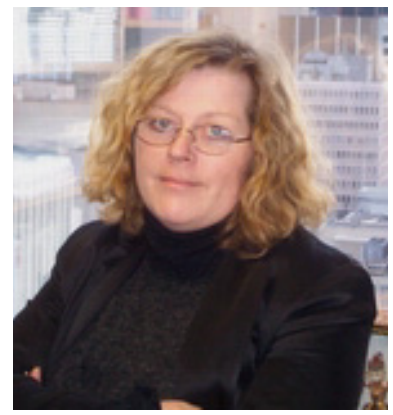

Dr. Joan Richardson is a Senior Lecturer in the School of Business IT and Logistics at RMIT University in Melbourne, Australia. She has worked on University projects aimed at maintaining a leading position in the application of ICT in the education sector, shifting effective use of technology into the mainstream and delivering state of the art courses and programs. She has published suites of digital curriculum based resources delivered using CDROM and Web formats and several texts, primarily designed to teach technology end-users information systems. She has also published widely in the educational technology domain in journals and conferences. Designing, developing and implementing new applications of technology to augment education is a key area of research. 